\title{
1 Cleavable ester linked magnetic nanoparticles for 2 labeling of solvent exposed primary amine groups of 3 peptides/proteins
}

4

5 Ujwal S. Patil,${ }^{\dagger}$ Laura Osorno, ${ }^{\dagger}$ Angela Ellender, ${ }^{\dagger}$ Casey Grimm, ${ }^{\#}$ and Matthew A Tarr ${ }^{\dagger}, *$

6

$7 \dagger$ Department of Chemistry, University of New Orleans, 2000 Lakeshore Drive, New Orleans, 8 Louisiana 70148, USA

\#Southern Regional Research Center, 1100 Robert E. Lee Blvd., New Orleans, Louisiana 70124, 11 USA

12

$13 *$ Corresponding author

14 E-mail: mtarr@uno.edu Tel: 504-282-6323

15

16

17

Short title: Ester linked nanomagnets for protein labeling 
31 In order to study the solvent exposed lysine residues of peptides/proteins, we previously reported

32 disulfide linked $N$-hydrosuccinimide ester modified silica coated iron oxide magnetic 33 nanoparticles (NHS-SS-SiO ${ }_{2} @ \mathrm{Fe}_{3} \mathrm{O}_{4} \mathrm{MNPs}$ ). The presence of a disulfide bond in the linker

34 limits the use of disulfide reducing agent during protein digestion and allows unwanted disulfide 35 formation between the MNP and protein. In the current work, the disulfide bond was replaced 36 with a cleavable ester group to synthesize NHS ester modified $\mathrm{SiO}_{2} @ \mathrm{Fe}_{3} \mathrm{O}_{4} \mathrm{MNPs}$. Use of the 37 cleavable ester group provides an improved method for protein labeling and allows use of 38 disulfide reducing agents during protein digestion.

39

40 Key-words: (Ethylene glycol bis[succinimidylsuccinate]), Core-shell magnetic nanoparticles, 41 Solvent exposed lysine residues 
The labeling of proteins using chemically cleavable amino acid specific probes coupled with mass spectrometric analysis remains a major choice to study the solvent accessible surface of proteins. The amino acid specific probes can specifically label the functional group of amino acids, and a cleavable bond assists with the isolation and identification of labeled proteins [1]. Variety of cleavable amino acid specific probes targeting the primary amine groups are developed due to abundance of lysine residues on the solvent accessible surface of proteins [2], [3]. The labeling probes containing NHS/sulfo-NHS groups can covalently label the primary amine groups of lysine residues in physiological buffers and at room temperature to form a stable amide bond [3]. The disulfide linked, lysine targeting cleavable labeling reagents are commercially available and have been widely used to obtain structural information of proteins. Upon labeling, proteins are digested using reducing agents (Dithiothreitol, DTT and tris(2carboxyethyl)phosphine), TCEP) that cleave disulfide bonds to unfold the protein structure which is required to denature the protein. Protein denaturation unfolds the protein in order to achieve the maximum efficiency for downstream processes such as tryptic digestion. The presence of disulfide bonds in the crosslinker may limit the use of reducing agents such as DTT and TCEP prior to protein digestion. Use of disulfide containing linkers is not compatible with DTT containing buffers and may be attacked by free thiol groups in complex cellular conditions. An alternative crosslinker, (Ethylene glycol bis[succinimidylsuccinate]) (EGS) could be an effective replacement for disulfide containing crosslinkers which can allow the use of disulfide cleaving reducing agents during protein digestion [4].

Upon labeling the functional groups of proteins, labeled proteins are separated and purified by using conventional electrophoretic, chromatographic or centrifugation techniques which could be time consuming, tedious, and detrimental to the structure of a protein [5]. Recently, the magnetic 
nanoparticles have emerged as an effective alternative to achieve rapid and effective separation for sample preparation in proteomics [6],[7]. In our lab, we have developed disulfide linked, NHS ester modified $\mathrm{SiO}_{2} @ \mathrm{Fe}_{3} \mathrm{O}_{4} \mathrm{MNPs}$ to 'label' the solvent exposed lysine residues of proteins [8] and yeast cell surface proteins [9]. The NHS/sulfo-NHS ester modified MNPs allowed labeling of lysine residues under physiological conditions at room temperature. The MNP based labeling approach offered rapid and soft magnetic separation of conjugated proteins which is advantageous over traditional protein separation techniques such as column chromatography and gel electrophoresis. However, the disulfide bond in the NHS-SS-SiO $\mathrm{S}_{2} \mathrm{Fe}_{3} \mathrm{O}_{4} \mathrm{MNPs}$ can be attacked by the reducing agents during protein digestion thereby cleaving the disulfide bond prior to the magnetic separation step. Moreover, an extra step of alkylation of free thiol groups needs to be added prior to the labeling process to protect disulfide groups in the linker. In this work, we replaced the cleavable disulfide bond with a cleavable ester bond to link NHS ester groups to the surface of $\mathrm{SiO}_{2} @ \mathrm{Fe}_{3} \mathrm{O}_{4} \mathrm{MNPs}$, and utilized ester linked, NHS ester modified MNPs to label the solvent exposed primary amine groups of proteins in its native state.

In this study, the $\mathrm{Fe}_{3} \mathrm{O}_{4}$ MNPs were prepared by a thermal decomposition method as reported earlier [10]. The $\mathrm{Fe}_{3} \mathrm{O}_{4}$ NPs were characterized by TEM and XRD (Fig 1A and Fig 1 in Ref. [13]). The $\mathrm{Fe}_{3} \mathrm{O}_{4}$ MNPs were spherical, uniform, and average diameter was found be $\sim 10$ nm (Fig 1A). The core shell $\mathrm{SiO}_{2} @ \mathrm{Fe}_{3} \mathrm{O}_{4} \mathrm{MNPs}$ were prepared by coating $\mathrm{Fe}_{3} \mathrm{O}_{4} \mathrm{MNPs}$ with silica by using a reverse microemulsion technique [11]. TEM characterization confirmed the spherical and core shell nature of $\mathrm{SiO}_{2} @ \mathrm{Fe}_{3} \mathrm{O}_{4}$ MNPs. The average diameter of $\mathrm{SiO}_{2} @ \mathrm{Fe}_{3} \mathrm{O}_{4}$ MNPs was $\sim 35 \mathrm{~nm}$ and showed stability in aqueous solvents (Fig. 1B). The $\mathrm{SiO}_{2} @ \mathrm{Fe}_{3} \mathrm{O}_{4} \mathrm{MNPs}$ were further modified with amine groups using (3-aminopropyl)triethoxysilane (APTES) [12]. Upon addition of amine groups onto the surface of $\mathrm{SiO}_{2} @ \mathrm{Fe}_{3} \mathrm{O}_{4} \mathrm{MNPs}$, the observed zeta 
100

101

102

103

104

105

106

107

108

109

110

111

112

113

114

115

116 117 conjugated to $\mathrm{SiO}_{2} @ \mathrm{Fe}_{3} \mathrm{O}_{4} \mathrm{MNPs}$ (Fig 4 in Ref. [13]). The amount of dansylcadaverine

potential changed from an original negative value $(-9 \pm 5 \mathrm{mV})$ to a positive value $(+23 \pm 5 \mathrm{mV})$ as observed by DLS analysis (Wyatt Technology Corporation, Santa Barbara, CA), confirming the attachment of amine groups to the surfaces. The superparamagnetic nature of amine coated $\mathrm{SiO}_{2} @ \mathrm{Fe}_{3} \mathrm{O}_{4} \mathrm{MNPs}$ was studied by using a vibrating sample magnetometer (Micro-Mag Model 3900, Princeton Measurements Corporation). Absence of magnetic hysteresis indicated that the coating on the iron oxide core did not affect the superparamagnetic properties (data not shown). A homobifunctional crosslinker, (ethylene glycol bis[succinimidylsuccinate], EGS) was utilized for conjugation of NHS ester groups on the surface of amine modified $\mathrm{SiO}_{2} @ \mathrm{Fe}_{3} \mathrm{O}_{4} \mathrm{MNPs}$ (Scheme 1 and Fig 2 in Ref. [13]). In order to avoid crosslinking between MNPs, a high concentration of EGS was maintained during the coupling reaction. The amine modified $\mathrm{SiO}_{2} @ \mathrm{Fe}_{3} \mathrm{O}_{4}$ MNPs were slowly added to a DMSO solution of EGS and allowed to react for 20 min. The NHS ester modified $\mathrm{SiO}_{2} @ \mathrm{Fe}_{3} \mathrm{O}_{4} \mathrm{MNPs}$ were magnetically separated, washed with ethanol three times, and dried under vacuum (Scheme 1 in Ref [13]). A depletion approach was used to quantify the active NHS ester groups on the surface of $\mathrm{SiO}_{2} @ \mathrm{Fe}_{3} \mathrm{O}_{4} \mathrm{MNPs}$. An amine containing flurophore, dansylcadaverine (excitation: $335 \mathrm{~nm}$ and emission: $513 \mathrm{~nm}$ ) was conjugated to NHS ester modified $\mathrm{SiO}_{2} @ \mathrm{Fe}_{3} \mathrm{O}_{4}$ MNPs, and the remaining amount of dansylcadaverine was fluorimetrically measured to determine the amount of dansylcadaverine conjugated to $\mathrm{SiO}_{2} @ \mathrm{Fe}_{3} \mathrm{O}_{4} \mathrm{MNPs}$ corresponds to active NHS ester groups on the surface of $\mathrm{SiO}_{2} @ \mathrm{Fe}_{3} \mathrm{O}_{4}$ MNPs. These studies indicated 694 available NHS ester binding sites per $1 \mathrm{mg}$ of $\mathrm{SiO}_{2} @ \mathrm{Fe}_{3} \mathrm{O}_{4} \mathrm{MNPs}($ Section 2.6 in Ref. [13]).

In order to investigate the ability of ester linked, NHS ester modified $\mathrm{SiO}_{2} @ \mathrm{Fe}_{3} \mathrm{O}_{4} \mathrm{MNPs}$ to label amine groups, a small peptide, ACTH (4-11) containing two amine groups (side chain of 
123 lysine residue and $N$-terminus) was chosen. The $\mathrm{NHS}$ ester modified $\mathrm{SiO}_{2} @ \mathrm{Fe}_{3} \mathrm{O}_{4} \mathrm{MNPs}_{(0.5}$

$124 \mathrm{mg})$ were mixed with $\mathrm{ACTH} 4-11(10 \mu \mathrm{g}$ in $100 \mu \mathrm{L}$ PBS, $\mathrm{pH}=7.4)$ at room temperature and 125 physiological $\mathrm{pH}$ for 40 min. Peptide conjugated MNPs were magnetically separated and washed 126 several times using magnetic separation. The ester bond was subsequently cleaved by subjecting 127 it to hydroxylamine treatment for $4 \mathrm{hrs}$ at $37^{\circ} \mathrm{C}$. (Scheme 1) EGS contains two ester sites that 128 can be cleaved under basic conditions using hydroxylamine to release ethylene glycol (Scheme 129 1). After cleaving the ester bond, the MNPs were separated by using a magnet, and the 130 supernatant was passed through a C18 zip tip column (EMD millipore, Billerica, MA) and dried. 131 The dried material was resuspended in a mixture of ACN (3\%) and formic acid (5\%) (100 $\mu 1)$ 132 and analyzed with LC/MS/MS using an Agilent 1200 LC system, an Agilent Chip Cube 133 interface, and an Agilent 6520 Q-TOF tandem mass spectrometer (Agilent Technologies, Santa 134 Clara, CA). The NHS ester labeling reaction introduced a mass shift of +115.09 Da for modified 135 primary amine groups of ACTH 4-11. Mass spectrometric analysis revealed the presence of 136 peptides containing two labeled amine groups (lysine residues and $\mathrm{N}$-terminus) or peptides 137 containing only one labeled amine group (either lysine residues or N-terminus). Doubly charged 138 as well as triply charged peptides of both the combinations were also found. (Fig 3 of Ref. [13]) 139 The $b$ and $y$ ions fragmented during CID were matched with the theoretically calculated $\mathrm{b}$ and $\mathrm{y}$ 140 ions. Presence of series of $b$ and $y$ ions in the mass spectra confirmed the amine label on the 141 peptide.

The ability of ester linked, NHS ester modified $\mathrm{SiO}_{2} @ \mathrm{Fe}_{3} \mathrm{O}_{4}$ MNPs to label solvent 143 exposed lysine residues of proteins was tested with two model proteins: bovine serum albumin 144 (BSA, PDB: 3v03) and $\beta$ lactoglobulin (PDB: 2Q2M). The proteins were chosen due to 145 availability of crystal structure of bovine serum albumin and $\beta$-lactoglobulin. The presence of 
146 primary amine groups on the surface of these model proteins made them a perfect candidate to 147 perform proof of concept studies with cleavable, ester linked, NHS ester modified $\mathrm{SiO}_{2} @ \mathrm{Fe}_{3} \mathrm{O}_{4}$ 148 MNPs. The labeling reaction was performed in a similar way as with the peptides. After 149 conjugating the proteins to MNPs, the remaining NHS ester groups were quenched by adding 150

151 The MNP-protein adducts were magnetically separated, washed and denatured using urea and 152 DTT followed by treatment with iodoacetamide to alkylate free thiol groups. The denatured 153 protein conjugated to MNPs was further subjected to tryptic digestion. The tryptic peptides were 154 isolated from MNPs by cleaving the ester group followed by magnetic removal of the MNPs. 155 (Section 2.4 of Ref. [13]) The supernatant containing labeled peptides was desalted using C18 156 zip-tip column (EMD millipore, Billerica, MA) and dried. Upon mass spectrometric analysis, 157 data files were processed by using an Agilent workstation equipped with Spectrum Mill software 158 (Agilent Technologies, Santa Clara, CA) for peptide sequencing and protein identification. The 159 parameters for database search were set as follows: differential mass increase of 115.09 Da for 160 lysine residues and unmodified N-termini, and 15.9 Da for possible oxidized methionine 161 residues. The number of missed cleavage sites was set to three. Ester linked, NHS ester modified $162 \mathrm{SiO}_{2} @ \mathrm{Fe}_{3} \mathrm{O}_{4}$ MNPs successfully labeled the lysine residues located on solvent accessible 163 surfaces of BSA and $\beta$ lactoglobulin (Fig 2). NHS ester modified $\mathrm{SiO}_{2} @ \mathrm{Fe}_{3} \mathrm{O}_{4} \mathrm{MNPs}$ labeled 164 four lysine residues in $\beta$ lactoglobulin (contains 16 lysine residues) and six lysine residues in 165 BSA (contains 58 lysine residues) (Fig. 2, Table 1). All the labeled lysine residues were found in 166 the middle of the cleaved peptide sequence since labeled lysine residues are not recognized as a 167 cleavage site by trypsin. In previous work, the captured peptides were released from the 168 nanoparticles by cleaving the disulfide linker (NHS-SS-SiO $\mathrm{S}_{2} \mathrm{Fe}_{3} \mathrm{O}_{4} \mathrm{MNPs}$ ) using TCEP. 
169 Because the disulfide cleaving agent (e.g. TCEP) cannot be used until this last step, disulfide 170 bonds in the protein could not be cleaved prior to trypsinization, which is often an important step 171 for protein digestion. Consequently, disulfide containing proteins might be difficult to analyze 172 using the disulfide-based MNPs approach. This limitation was overcome in the current work by 173 replacement of the disulfide linker with an ester linker.

174 To conclude, cleavable ester linked, NHS ester modified MNPs were successfully used to 175 label solvent exposed amine groups of BSA and $\beta$-lactoglobulin. The presence of the ester bond 176 allowed digestion of MNPs-conjugated proteins in the presence of disulfide bond reducing agent, 177 DTT. Moreover, protein digestion can be more effectively carried out since disulfide cleavage 178 and protection with iodoacetamide allow better access by the proteolytic enzyme. Replacing the 179 disulfide linker with an ester linker makes the new labeling reagent a promising tool for cellular 180 systems that require digestion in the presence of reducing agents such as DTT or TCEP. The 181 work presented here provides opportunities for future studies of solvent exposed amine residues 182 of complex and heterogeneous cell surface/cell wall proteins and lipoproteins using cleavable 183 ester linked NHS ester modified $\mathrm{SiO}_{2} @ \mathrm{Fe}_{3} \mathrm{O}_{4} \mathrm{MNPs}$. These MNPs can also be applied to study 184 complex protein mixtures.

\section{Acknowledgements}

188 L. Osorno was supported by a National Science Foundation Research Experiences for 189 Undergraduates site (DMR-1004869 and DMR-1262904). We would like to thank Dr. Leonard 190 Spinu for his help with magnetization measurements of magnetic nanoparticles. 


\section{$192 \quad$ Figure legends}

193

194

195

196 solvents.

197 Fig 2: Labeled lysine residues (blue) of BSA (left top) and $\beta$ lactoglobulin (left bottom) with 198 ester linked, NHS ester modified $\mathrm{SiO}_{2} @ \mathrm{Fe}_{3} \mathrm{O}_{4} \mathrm{MNPs}$.

199 Scheme 1: Labeling of amine containing peptides using cleavable ester linked, NHS ester

200 modified $\mathrm{SiO}_{2} @ \mathrm{Fe}_{3} \mathrm{O}_{4} \mathrm{MNPs}$.

201 Table 1: List of tryptic peptides with labeled lysine residues (represented k).
202

203

204

205

206

207

208

209

210 


\section{References}

213

214 [1] G. Leriche, L. Chisholm, A. Wagner, Cleavable linkers in chemical biology. Bioorg. 215

216

217

218

219

220

221

222

223

224

225

226

227

228

229

230

231 Med. Chem. 20 (2012) 571-582. doi:10.1016/j.bmc.2011.07.048.

[2] V.L. Mendoza, R.W. Vachet, Probing protein structure by amino acid-specific covalent labeling and mass spectrometry. Mass Spectrom. Rev. 28 (2009) 785-815. doi:10.1002/mas.20203.

[3] G.T. Hermanson, Bioconjugate Techniques, Academic Press, San Diego, 1996.

[4] P.M. Abdella, P.K. Smith, G.P. Royer, A new cleavable reagent for cross-linking and reversible immobilization of proteins. Biochem. Biophys. Res. Commun. 87 (1979) 734742.

[5] I. Safarik, M. Safarikova, Magnetic techniques for the isolation and purification of proteins and peptides. Biomagnetic research and technology 2:7 (2004). doi:10.1186/1477-044X-2-7.

[6] J. He, M. Huang, D. Wang, Z. Zhang, G. Li, Magnetic separation techniques in sample preparation for biological analysis: A review. J. Pharm. Biomed. Anal.101 (2014) 84101. doi:http://dx.doi.org/10.1016/j.jpba.2014.04.017.

[7] Y. Li, X. Zhang, C. Deng, Functionalized magnetic nanoparticles for sample preparation in proteomics and peptidomics analysis. Chem. Soc. Rev. 42 (2013) 8517-8539. doi:10.1039/c3es60156k. 
232 [8] U.S. Patil, H. Qu, D. Caruntu, C.J. O'Connor, A. Sharma, Y. Cai, M.A. Tarr, Labeling

233 Primary Amine Groups in Peptides and Proteins with N-Hydroxysuccinimidyl Ester Modified $\mathrm{Fe}_{3} \mathrm{O}_{4} @ \mathrm{SiO}_{2}$ Nanoparticles Containing Cleavable Disulfide-Bond Linkers. Bioconjugate Chem. 24 (2013) 1562-1569. doi:10.1021/bc400165r.

[9] U.S.Patil, P.Pirani, Y. Cai, M. A. Tarr. Profiling yeast cell surface proteins of $S$. cerevisae by magnetic nanoparticles based covalent labeling of amine groups. $62^{\text {nd }}$ ASMS Conference on Mass Spectrometry and Allied Topics.

[10] W.W. Yu, J.C. Falkner, C.T. Yavuz, V.L. Colvin, Synthesis of monodisperse iron oxide nanocrystals by thermal decomposition of iron carboxylate salts. Chem. Comm. (2004) 2306-2307. doi:10.1039/B409601K

[11] S. Santra, R. Tapec, N. Theodoropoulou, J. Dobson, A. Hebard, W. Tan, Synthesis and Characterization of Silica-Coated Iron Oxide Nanoparticles in Microemulsionthe Effect of Nonionic Surfactants. Langmuir 17 (2001) 2900-2906. doi:10.1021/la0008636

[12] K. Can, M. Ozmen, M. Ersoz, Immobilization of albumin on aminosilane modified superparamagnetic magnetite nanoparticles and its characterization. Colloids Surf., B 71 (2009) 154-159. doi:http://dx.doi.org/10.1016/j.colsurfb.2009.01.021

[13] U.S. Patil, L. Osorno, A. Ellender, C. Grimm and M. A. Tarr, Cleavable ester linked magnetic nanoparticles for labeling of solvent exposed primary amine groups of peptides/proteins. Data in brief, Submitted (2015) 


\section{Figure 1}
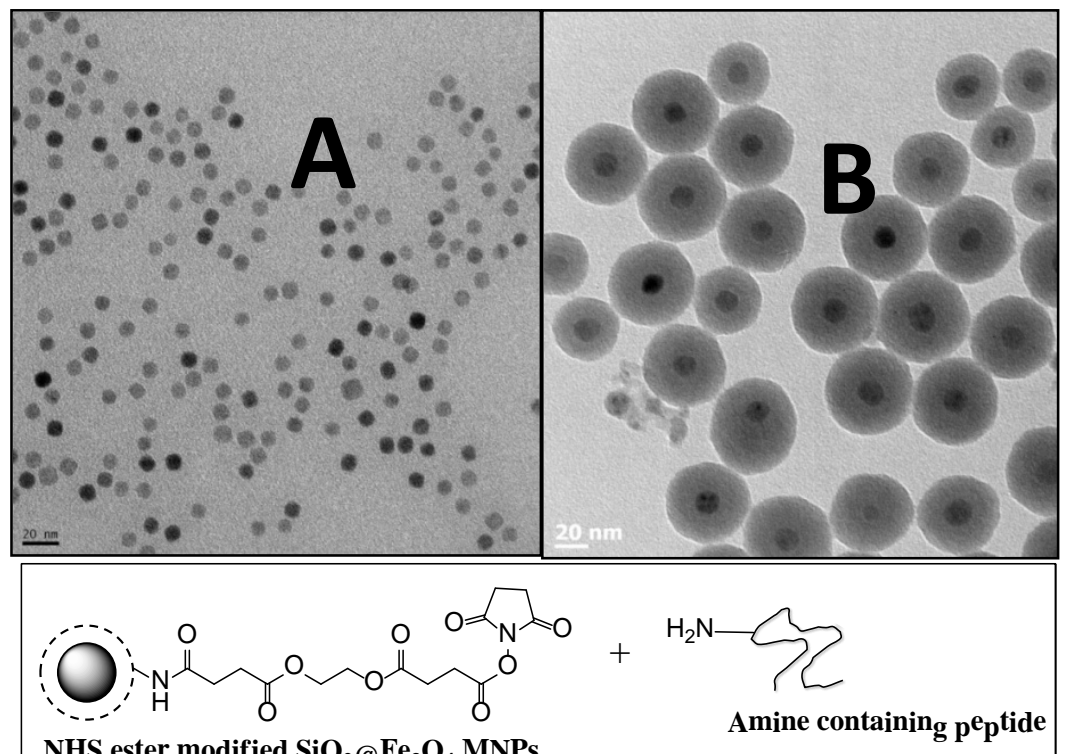

NHS ester modified $\mathrm{SiO}_{2} @ \mathrm{Fe}_{3} \mathrm{O}_{4} \mathrm{MNPs}$
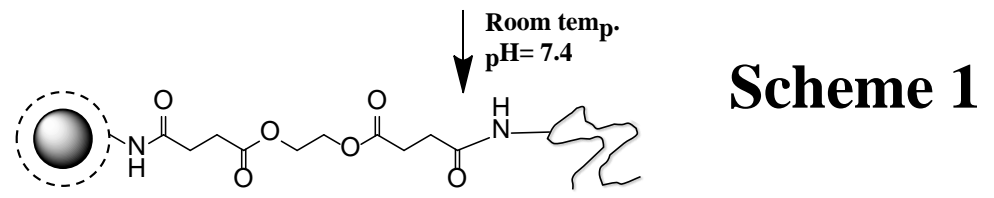

Scheme 1

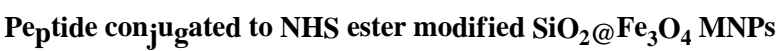

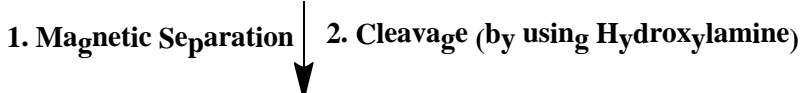

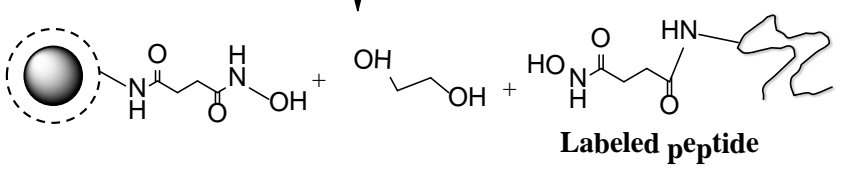


Figure 2

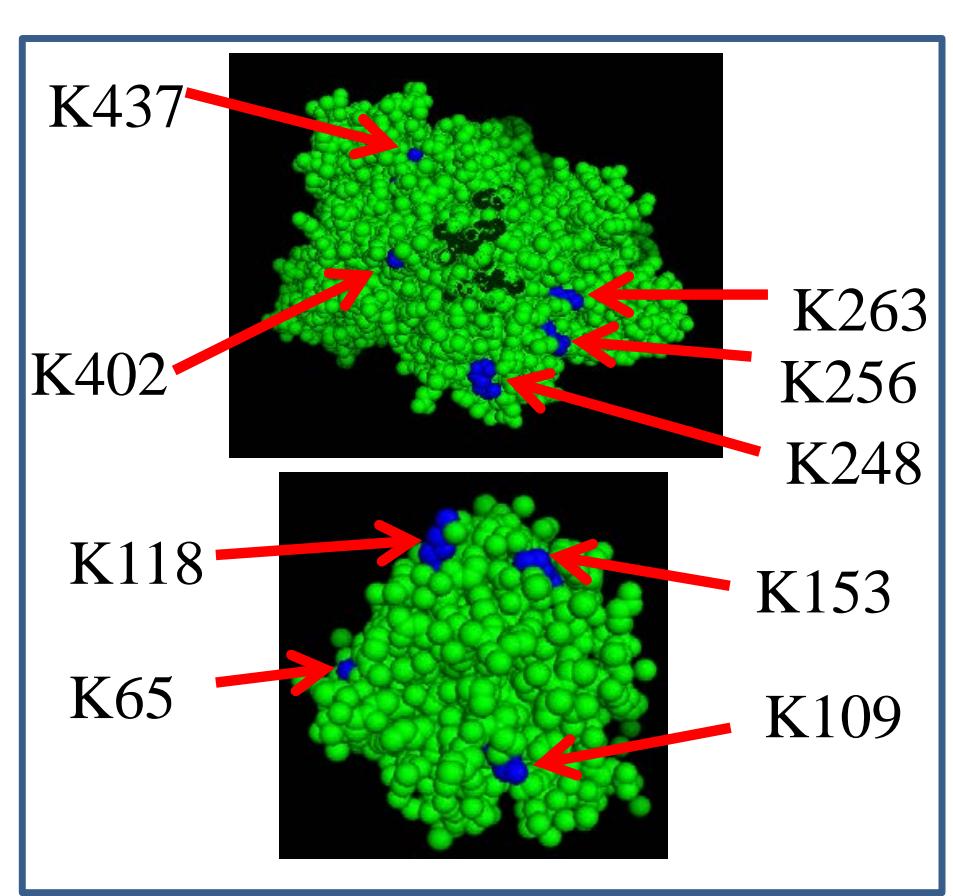




\section{Table 1}

\begin{tabular}{|l|l|l|l|}
\hline $\begin{array}{l}\text { Name of a } \\
\text { protein }\end{array}$ & $\begin{array}{l}\text { Labeled } \\
\text { peptides }\end{array}$ & Sequence of labeled peptides & Score \\
\hline & & & \\
\hline BSA & & & \\
\hline & $452-459$ & (R)SLGkVGTR(C) & 69.9 \\
\hline & $257-266$ & (K)LVTDLTkVHK(E) & 61.1 \\
\hline & $400-413$ & (K)LkHLVDEPQNLIK(Q) & 62 \\
\hline & $242-256$ & (R)LSQKFPkAEFVEVTK(L) & 64.7 \\
\hline & $249-263$ & (K)AEFVEVTkLVTDLTK(V) & 65.6 \\
\hline & $437-451$ & (R)kVPQVSTPTLVEVSR(S) & 91.1 \\
\hline$\beta$ lactoglobulin & & & \\
\hline & $59-78$ & (R)VYVEELkPTPEGDLEILLQK(W) & 86.9 \\
\hline & $110-119$ & (K)VLVLDTDYkK(Y) & 75.3 \\
\hline & $102-118$ & (K)IDALNENkVLVLDTDYK(K) & 62.3 \\
\hline & $143-156$ & (R)TPEVDDEALEkFDK(A) & 69.4 \\
\hline
\end{tabular}

